Nepalese Vet. J. 35:1-8

\title{
Effectiveness of Different Hormonal Treatment Protocols on Treatment of Postpartum Anoestrus in Cross-Bred Dairy Cows
}

\author{
P. K. Rana ${ }^{1}$, G. Gautam ${ }^{1 *}$, B. Devkota ${ }^{1}$, S. K. Shah ${ }^{1}$, S. Barsila ${ }^{2}$ and I. P. Kadariya ${ }^{3}$ \\ ${ }^{1}$ Department of Theriogenology, Agriculture and Forestry University, Rampur, Chitwan, Nepal. \\ ${ }^{2}$ Department of Animal Nutrition, Agriculture and Forestry University, Rampur, Chitwan, Nepal. \\ ${ }^{3}$ Center for Biotechnology, Agriculture and Forestry University, Rampur, Chitwan, Nepal. \\ *Corresponding author: gogautam@afu.edu.np
}

\begin{abstract}
Postpartum anoestrus (PPA) is one of the major factors causing prolonged calving interval \& that leading to decreased annual milk production. Hormonal treatments can be effective tools for treatment of PPA when nutritional \& environmental management are good. So, objective of this study was to know the comparative effectiveness of different hormonal protocols on treatment of PPA in cross-bred dairy cows. Used protocols were: single dose of GnRH, Ovsynch with TRIU-B and single dose of PGF ${ }_{2} \alpha$ injection which were used in three different groups, each containing ten animals. GnRH and Ovsynch with TRIU-B were used in postpartum true anoestrus cattle with inactive ovaries while PGF 2 a was used in postpartum silent oestrus condition having palpable corpus luteum and the condition were identified through rectal palpation and history record. Cows treated with Ovsynch+TRIU-B showed higher oestrus expression rate within one week (80\%) than cows treated with GnRH (10\%) and $\mathrm{PGF}_{2} \alpha(50 \%)$. Ovulation rate was also comparatively higher in Ovsynch + TRIU-B group (100\%) than GnRH (90\%) and $\mathrm{PGF}_{2} \alpha(70 \%)$. But the pregnancy rate, checked after 45 days of first AI through rectal palpation, was comparatively higher in $G n R H$ group (40\%) than in Ovsynch+TRIU-B (30\%) and PGF $\alpha$ (20\%). Among treated cows, pregnancy rate was found to be significantly higher $(P=0.02)$ in cows with $\geq 100$ days duration of postpartum anoestrus (53.84\%) than in cows with 100 days duration (0\%). In conclusion, ovsynch with intravaginal progesterone ( 4 ) releasing device was more effective at inducing oestrus and synchronizing ovulation than the single GnRH injection. However, single GnRH injection was as effective as ovsynch with intravaginal $p 4$ releasing device for pregnancy outcomes in anoestrous crossbred dairy cows in a commercial dairy farm where formulated concentrate ration is daily fed.
\end{abstract}

Keywords: hormonal protocols; oestrous synchronization; pregnancy rates; silent estrus; true anoestrus 


\section{INTRODUCTION}

In Nepal infertility/anoestrus problem in crossbred and exotic cattle has been reported to be the most prioritized problem in dairy pocket areas in the country (Jha, 2000). Fertility and breeding efficiency of dairy animals play a pivotal role in dairy economics (Peter et al., 2009). Cows are regarded as physiologically anoestrous for a few days following parturition, whereas, lack of oestrus after 60 days postpartum is considered pathological anoestrus or extended postpartum anoestrus (Islam et al., 2013). In general, a calving interval of about 1 year is considered economically optimal for dairy cows (Schmidt, 1989). To achieve such a calving interval, a postpartum cow has to resume ovarian activity, to be observed in heat, to be mated, and to conceive within 85 days after calving (Lamming, 1981). It has been suggested that in high-yielding dairy herds, there is increased incidence of anoestrous (Berger et al., 1981). However, factors such as limited energy intake, lower body reserves, hormonal imbalance and postpartum diseases can also delay the return to cyclicity (Opsomer et al., 2000). As it is known that follicle maturation, ovulation or ovarian cyclicity are energy as well as hormonal dependent process, negative energy balance and hormonal insufficiency frequently cause inactive ovaries i.e. postpartum true anoestrus for long time period. Similarly, sometime although there is ovulation timely after calving, the animal can't express heat; called as postpartum silent oestrus (Opsomer et al., 2000). In commercial farms where they use commercial feeds to overcome energy deficit, in this condition hormonal imbalance and high lactation/ production stress may cause temporary cessation of hypothalamus-hypophysial axis leading to inactive ovaries or sub-active ovaries. In such cases treatment with appropriate hormonal protocols can be effective tools to resume the cyclicity in postpartum anoestrus dairy cows or make them conceived. In Nepalese context, there was very few research works have been performed in dairy cattle reproduction; there are no well documented reports on treatment of postpartum anoestrus cows using hormonal protocols. Therefore, this study was designated to evaluate the efficacy of different oestrus synchronization protocols using hormones to overcome this postpartum anoestrus problem in dairy cattle of Nepal.

\section{MATERIALS AND METHODS}

This study was conducted in a commercial dairy farm located in chitwan district and 105 postpartum cows were selected as study samples, that had not shown oestrous behaviour upto 60 days postpartum and had not mated yet, using their history record. Among all the postpartum anoestrus cattle, some were selected randomly and examined by trans-rectal palpation of genital organs. They were classified as true anoestrus (having no palpable CL and small follicles i.e. $<5 \mathrm{~mm}$ ) and silent oestrus 
(having palpable CL and large follicles). Among true anoestrus cattle 10 were treated with single GnRH injection (day 0 Gynarich inj. $5 \mathrm{ml}$ i.e. $20 \mu \mathrm{g}$ Buserelin acetate I/M was given, waited for oestrous expression and AI was done) and 10 were treated with Ovsynch with TRIU-B/progesterone impregnated intravaginal device (day 0 Gynarich 5ml I/M and vaginal insertion of TRIU-B for 7 day, at day 7 Lutalyse inj $5 \mathrm{ml}$ I/M i.e. $25 \mathrm{mg}$ Dinoprost tromethamine was given and TRIU-B was removed, at day 9 Gynarich $5 \mathrm{ml}$ was given and at day 10 FTAI was done). Among silent oestrus cattle 10 were treated with single PGF2 $\alpha$ injection (day 0 lutalyse $5 \mathrm{ml} \mathrm{I} / \mathrm{M}$ was given and waited for oestrus expression and AI was done). The research activities are shown in detail in figure 1.

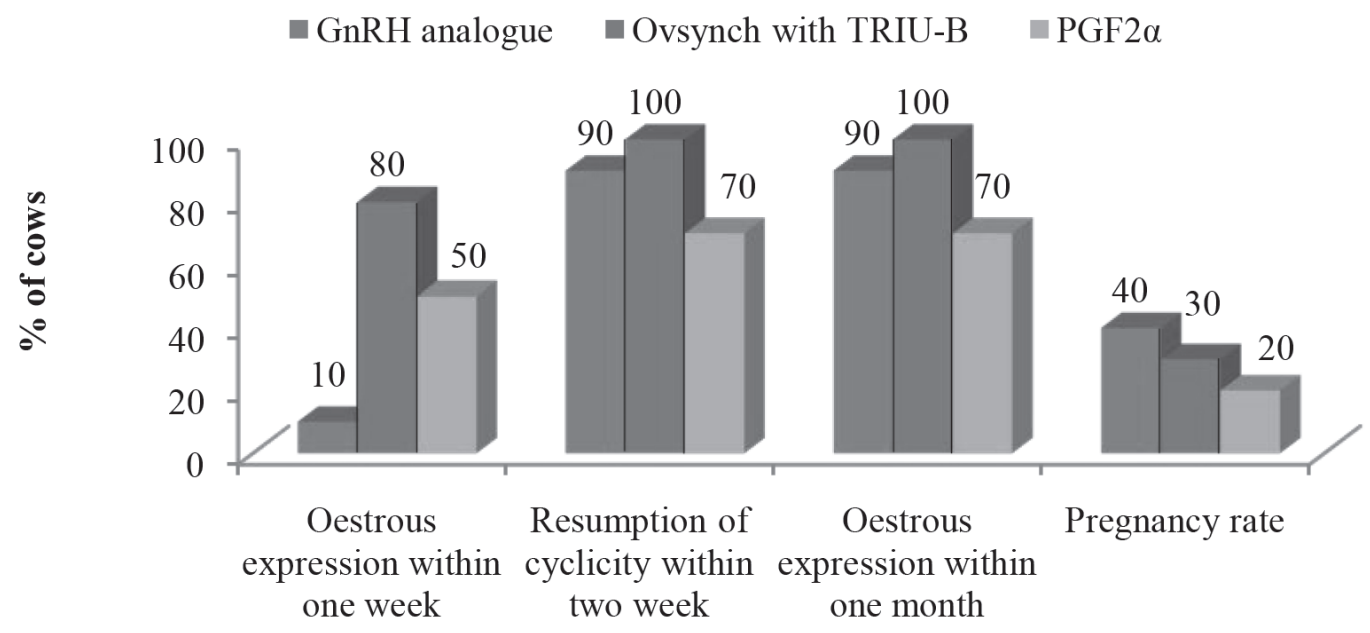

Fig. 1: Comparative Effectiveness of different hormonal treatment protocols on postpartum anoestrus.

Chi-square test and Fisher's exact test in IBM SPSS Statistics version 20 were utilized to know the success rate of different treatment protocols on postpartum anoestrous. Similarly, MS-EXCEL-2007 was used for data entry and making different diagrams.

\section{RESULTS AND DISSCUSSION}

\section{Effect of different hormonal treatment protocols on postpartum anoestrus}

The oestrous expression rate within one week was found to be significantly higher in Ovsynch-TRIU-B treated cows $(80 \%$ vs $10 \%)$ than in single GnRH inj. treated cows $(\mathrm{P}=0.003)$. Resumption of cyclicity or ovulation rate within two week and oestrous expression rate within one month was found to be very similar between cows treated with GnRH, TRIU-B and $\mathrm{PGF}_{2} \alpha$ i.e. $90 \%, 100 \%$ and $70 \%$ respectively. Pregnancy rate was found to be comparatively higher in $\mathrm{GnRH}$ treated cows than 
Ovsynch+TRIU-B treated and $\mathrm{PGF}_{2} \alpha$ treated cows i.e. $40 \%, 30 \%, 20 \%$ respectively. The detailed data was presented in Table 1 .

Table 1: Effect of different treatment protocols on postpartum anoestrus.

\begin{tabular}{|c|c|c|c|c|c|}
\hline \multirow{3}{*}{ Parameters } & \multicolumn{4}{|c|}{ Treatment group } & \multirow{3}{*}{$\begin{array}{l}\text { Total } \\
(\mathbf{n}=\mathbf{3 0})\end{array}$} \\
\hline & \multicolumn{3}{|c|}{ True anoestrus } & \multirow{2}{*}{$\begin{array}{c}\text { Silent oestrus } \\
\text { PGF2 } \alpha \\
\text { Group } \\
(\mathbf{n}=10)\end{array}$} & \\
\hline & $\begin{array}{l}\text { GnRH } \\
\text { group } \\
(\mathrm{n}=10)\end{array}$ & $\begin{array}{c}\text { Ovsynch } \\
\text { with TRIU-B } \\
(n=10) \\
\end{array}$ & P value & & \\
\hline $\begin{array}{l}\text { Oestrus } \\
\text { expression } \\
\text { within } 1 \mathrm{wk}(\%)\end{array}$ & $1(10)$ & $8(80)$ & 0.003 & $5(50)$ & $14(46.7)$ \\
\hline $\begin{array}{l}\text { Resumption of } \\
\text { ovarian cyclicity } \\
\text { within } 2 \text { wk ( } \%)\end{array}$ & $9(90)$ & $10(100)$ & 0.5 & $7(70)$ & $26(86.7)$ \\
\hline $\begin{array}{l}\text { Oestrus } \\
\text { expression } \\
\text { within } 1 \text { month } \\
\text { and AI done (\%) }\end{array}$ & $9(90)$ & $10(100)$ & 0.5 & $7(70)$ & $26(86.7)$ \\
\hline $\begin{array}{l}\text { Pregnancy rate } \\
\text { after first AI }(\%)\end{array}$ & $4(40)$ & $3(30)$ & 0.5 & $2(20)$ & $9(30)$ \\
\hline
\end{tabular}

GnRH=Gonadotropin Releasing Hormone; TRIU-B = Progesterone Impregnated Intravaginal Device manufactured by Virbac company; $\mathrm{PGF}_{2} \alpha=$ Prostaglandin $\mathrm{F}_{2} \alpha$ or its analogue; $\mathrm{P}$ value $=$ Degree of association between $\mathrm{GnRH}$ group and Ovsynch+TRIU-B group; wk= week; AI=Artificial Insemination

In case of GnRH, Islam et al (2013) found 75\% oestrous expression rate and Shah and Nakao (2010) found 100\% oestrous expression rate with single injection of GnRH in dairy cows and in buffalo respectively which are significantly higher than this finding (10\%). Similarly, Islam et al., (2013) and Wiltbank et al., (1997) found 76.5\% and $85 \%$ ovulation rate within one month with single injection of GnRH which are very similar to this finding $(90 \%)$.

Table 2: Effect of duration of postpartum anoestrus on treatment response against postpartum true anoestrus in dairy cows. 


\begin{tabular}{llllll}
\hline Parameters & Categories & $\begin{array}{c}\text { Total } \\
\text { no. }\end{array}$ & $\begin{array}{c}\text { Oestrus } \\
\text { expression } \\
\text { within 15 days }\end{array}$ & $\begin{array}{c}\text { Oestrus } \\
\text { expression } \\
\text { wihin 30 days }\end{array}$ & $\begin{array}{c}\text { Conception } \\
\text { rate after first } \\
\text { AI }\end{array}$ \\
\hline $\begin{array}{l}\text { Duration of } \\
\text { anoestrous }\end{array}$ & 100 days & 7 & $5(71.43 \%)$ & $6(85.71 \%)$ & $0(0 \%)$ \\
& & & $9(69.23 \%)$ & $13(100 \%)$ & $7(53.84 \%)$ \\
P value & & 0.66 & 0.35 & $\mathbf{0 . 0 2}$ \\
\hline
\end{tabular}

Similarly, Islam et al., (2013) found 64.7\% and Shah and Nakao (2010) found $90.9 \%$ conception rate with single injection of GnRH in dairy cows and buffaloes respectively which are comparatively higher than this finding (40\%). Thus, present study has demonstrated that a single injection of GnRH analogue had positive effect on induction of oestrus and conception in anoestrus cows. GnRH and its agonist act on ovarian follicular development and CL formation indirectly via the induced release of pituitary LH and FSH. Administration of GnRH causes the large follicles to ovulate and induces emergence of a new follicular wave within 3 to 4 days after treatment at any stage of the oestrous cycle in cattle.

In case of $\mathrm{PGF}_{2} \alpha$, very similar findings was obtained by Rasaili et al., (2002) who found $60 \%$ oestrous expression rate and $20 \%$ conception rate with first injection of $\mathrm{PGF}_{2} \alpha$ in stall-fed dairy herd in Lumle. But Islam et al., (2013) and Shah and Nakao (2010) found comparatively higher oestrous expression rate i.e. $73.9 \%$ and $100 \%$ respectively. Similarly, they also found higher conception rate i.e. $52.1 \%$ and $86.4 \%$ respectively with single injection of $\mathrm{PGF}_{2} \alpha$ in dairy cows and buffaloes respectively. $\mathrm{PGF}_{2} \alpha$ and its analogue act on CL, formed on ovary which cause temporary cessation of oestrous cycle. So lysis of CL cause beginning of new oestrous cycle within 1 week.

In case of Ovsych with TRIU-B protocol, same findings was obtained by Ramakrishnan et al., (2012) i.e. 100\% oestrous expression rate and 33.3\% conception rate in first time AI with Ovsynch CIDR protocol. Similar result was also found by Zabeel et al., (2009) and Bhoraniya et al., (2012) in buffaloes and Kankrej cows, respectively i.e. $100 \%$ oestrous expression rate. In contrary, Tauck et al., (2007) and Cevik et al., (2010) found $43 \%$ to $83 \%$ oestrous expression rate which was lower than this finding. Similarly, Martinez et al., (1998) found 60\%, Cevik et al., (2010) found $53.3 \%$ and Tauck et al., (2007) found 69\% conception rate with Ovsynch CIDR protocol in dairy cows which are higher than this finding. Better oestrus response 
and conception rate in TRIU-B group could be due to progesterone priming through TRIU-B, establishment of proper endocrine harmony/ synchrony and FTAI. While difference in conception rate in different findings might be due to quality of semen, experience of technician etc.

\section{Duration of anoestrous and treatment response against postpartum true anoestrus in dairy cows}

It was found that cows with more than 100 days postpartum duration showed comparatively higher oestrous expression rate $(100 \% \mathrm{vs} 85.71 \%)$ and significantly higher conception rate $(53.84 \% \mathrm{vs} 0 \%)$ within 30 days of treatment than cows with less than 100 days postpartum duration. The detailed was given in table 2. It might be due to overcome/resumption of negative energy balance and reproductive cyclicity after 100 days of postpartum, so that hormones have worked properly and conception was not lost.

\section{CONCLUSION}

This study found no significantly difference in Conception rate on treatment of postpartum anoestrus with these three hormonal protocols $\left(\mathrm{GnRH}, \mathrm{PGF}_{2} \alpha\right.$ and Ovsynch with TRIU-B), however GnRH and $\mathrm{PGF}_{2} \alpha$ injection can be used efficiently in small herd size where oestrous detection is not a problem and it is less costly also while Ovsynch with TRIU-B was found to be better for large commercial farms where oestrous detection always seems a problem. Similarly, success rate of hormonal protocols was found to be more in $>100$ days postpartum cows than $<$ 100 days postpartum. So, postpartum reproductive rest up to 3 months is required to increase oestrous expression rate as well as conception rate.

\section{ACKNOWLEDGEMENT}

We are grateful to the Nepal Academy of Science and Technology (NAST) for providing financial support for conducting this research. We would like to acknowledge National Agriculture Research Development Fund (NARDF) Sinhadarbar plaza, Kathmandu, Nepal, for providing MVSc fellowship Thesis grant to P. Rana. Laliguras Dairy cattle farm, Chitwan, Nepal was acknowledged for providing us their well-managed dairy cattle farm to conduct this research. AFU second batch Theriogenology group members, Dr. Shatrughan Shah, Dr. Ram Chandra Sapkota and Dr. Bidur Prasad Gautam are also acknowledged for their cooperation. 


\section{REFERENCES}

Berger BJ, Shanks RD, Freeman AE, Laben RC (1981). Genetic aspects of milk yield and reproductive performance. J Dairy Sci 1981; 64:114-22.

Bhoraniya, H.L., Dhami, A.J., Naikoo, M., Parmar, B.C. and Sarvaiya, N.P (2012). Effect of estrus synchronization protocols on plasma progesterone profile and fertility in postpartum anestrous Kankrej cows. Trop. Anim. Health Prod., 44(3): online, DOI 10.1007/s11250-011-0057-1.

Cevik, M., Selcuk, M. and Dogan, S. (2010). Comparison of pregnancy rates after timed artificial insemination in Ovsynch, Heatsynch and CIDR-based synchronization protocol in dairy cows. Kafkas. Univ. Vet. Fak. Derg; 16(1): 85-89.

Jha, V.C. (2000) Study on infectious causes of infertility in crossbred \& exotic cattle in Nepal. Annual Report (1999/2000), Animal Health Research Division, Tripureswor: 19-23.

Lamming GE, Wathes DC, and Peters AR (1981). Endocrine patterns of the postpartum cow. J Reprod Fertil 1981; 30: 155-70.

M. R. Islam, N. S. Juyena1*, M. M. U. Bhuiyan, M. M. Rahman and R. N. Ferdousy, (2013). Treatment outcomes in postpartum anoestrus cows Guided by transrectal ultrasonography. Progress. Agric. 24(1 \& 2): 93 - 100, 2013.

Martinez, M.F., Kastelic, J.P., Adams, G.P., Janzen, E., Olson, W. and Mapletoft, R.J. (1998). Alternative methods of synchronizing estrus and ovulation for fixed time insemination in cattle. Theriogenolgy, 50: 350.

Opsomer G, Grohn YT, Hertl J, Coryn M, Deluyker H, de Kruif A (2000). Risk factors for post-partum ovarian dysfunction in high producing dairy cows in Belgium: a field study. Theriogenology 2000; 53:841-57.

Peter, A.T., Vos, P.L. and Ambrose, D.J. (2009). Postpartum anoestrus in dairy cattle. Theriogenology, 71: 1333-1342.

Ramakrishnan, A., Dhami A.J., Naikoo, M., Parmar, B.C., And Divekar, B.S., (2012). Estrus induction and fertility response in postpartum Anestrus gir cows. Indian Journal of Animal Reproduction 33 (1): June 2012

Rasali, D.P. et al., (2002). An attempt to synchronize oestrus in on-station and onfarm local cows for mass insemination in the western mid hills. Nepalese Vet. 
Journal - 2002, Nepal Veterinary Association (NVA). Pages; 34-42.

Sah and Nakao, (2010). A clinical study of anoestrous buffaloes in southern Nepal. Journal of Reproduction and Development, Vol. 56, No. 2, 2010.

Schmidt GH, (1989). Effect of length of calving intervals on income over feed and variable costs. J Dairy Sci 1989; 72: 1605-11.

Tauck, S.A., Wilkinson, J.R.C., Olsen, J.R. and Berardinelli, J.G. (2007). Comparison of using 7- or 14-d CIDR treatments in an estrous synchronization protocol that included PGF2á, timed A I and GnRH in primiparous, suckled beef cows. Proc. Western Section, Am. Soc. Anim. Sci., 58: 271-273.

Wiltbank, M. C. 1997. How information on hormonal regulation of the ovary has improved understanding of the timed breeding programs. In: Proceed. Annual Meeting of Society for Theriogenology, Montereal, Canada. 83-97.

Zabeel, S.M., Hegab, A.O., Montasser, A.E. and El-Sheikh, H. (2009). Reproductive performance of anestrous buffaloes treated with CIDR. 